\title{
HEMATOLOGY AND BLOOD CHEMISTRY OF WINTERING COMMON CRANES ${ }^{1}$
}

\author{
M. L. Puerta \\ Departmento de Biología Animal II (Fisiología Animal), Facultad de Ciencas Biológicas, \\ Universidad Complutense, 28040 Madrid, Spain \\ J. C. Alonso \\ Museo Nacional de Ciencias Naturales CSIC, José Gutiérrez Abascal 2, \\ 28006 Madrid, Spain \\ V. HUECAS \\ Departmento de Biología Animal II (Fisiologia Animal), Facultad de Ciencias Biológicas, \\ Universidad Complutense, 28040 Madrid, Spain \\ J. A. Alonso \\ Departmento de Biología Animal I (Vertebrados), Facultad de Ciencias Biologicas, \\ Universidad Complutense, 28040 Madrid, Spain \\ M. ABELENDA \\ Departmento de Biología Animal II (Fisiologia Animal), Facultad de Ciencias Biológicas, \\ Universidad Complutense, 28040 Madrid, Spain \\ R. Munoz-Pulido \\ Departmento de Biología Animal I (Vertebrados), Facultad de Ciencias Biológicas, \\ Universidad Complutense, 28040 Madrid, Spain
}

\begin{abstract}
We studied the hematology and blood chemistry of wintering Common Cranes (Grus grus). Red cell numbers $\left(2.460 \times 10^{6} \mathrm{~mm}^{-3}\right)$, hemoglobin content $(14.8 \mathrm{~g} / 100 \mathrm{ml})$, and hematocrit $(42.9 \%)$ were similar in adult and young birds. Young birds have significantly higher leukocyte numbers $\left(28 \times 10^{3} \mathrm{~mm}^{-3}\right)$ than adults $\left(22 \times 10^{3} \mathrm{~mm}^{-3}\right)$. Heterophils are the most abundant white blood cells in adults $(55 \%)$ whereas young have the same proportion of heterophils and lymphocytes (47\%). Plasma protein levels are similar in young and adult birds $(4.9 \mathrm{~g} / 100 \mathrm{ml})$, as is the plasma cholesterol level $(200 \mathrm{mg} / 100 \mathrm{ml})$. However, adults have higher plasma urea levels and lower uric acid and plasma triglyceride levels than young birds ( 7.1 vs. $5.5 \mathrm{mg} / 100 \mathrm{ml}, 2.9$ vs. $4.4 \mathrm{mg} / 100 \mathrm{ml}$, and $81 \mathrm{vs.} 110 \mathrm{mg} / 100 \mathrm{ml}$, respectively).
\end{abstract}

Key words: Common Cranes; erythrocytes; leukocytes; hemoglobin; plasma proteins; plasma lipids; plasma nitrogenous wastes.

\section{INTRODUCTION}

Most avian hematology studies have been undertaken in domestic birds, mainly fowl (Jones and Johansen 1972, Hodges 1979, DieterlenLievre 1988), although several wild birds have also been examined (for review see Sturkie 1986a). Sex and age differences have been described for many species although diet, hormone, and environment are known to influence blood cell absolute and relative numbers. On the other hand, it has been shown that migratory species

\footnotetext{
${ }^{1}$ Received 10 July 1989 . Final acceptance 1 November 1989.
}

present seasonal changes in several blood components and that such changes also occur in captive animals (Kern et al. 1972, Chilgren and deGraw 1977, deGraw et al. 1979).

The Common Crane (Grus grus) is a migratory species with a Eurasian distribution (Cramp and Simmons 1980). The western population winters in Iberia and Northern Africa. Gallocanta Lake (northeastern Spain) is the main stopover area of this population on its way to the winter quarters in southwestern Spain and North Africa (Alonso et al. 1984a). This allowed us to obtain blood samples from animals captured for banding in Gallocanta and therefore to get insight on hematology and plasma chemistry of wild, freeliving cranes during their stay in this locality. 


\section{MATERIALS AND METHODS}

Cranes were captured between November 1988 and January 1989 in Gallocanta $\left(40^{\circ} 58^{\prime} \mathrm{N}\right.$, $1^{\circ} 30^{\prime} \mathrm{W}$ ) by baiting food with $\alpha$-chloralose. Blood (1-2 ml) was collected from the radial vein with heparinized syringes. Body weight was also measured with a field balance. Sexual differentiation was not possible in the field since body measurements of the sexes overlapped. Adults and young were distinguished by differences in their plumage.

Blood was carefully transferred to a collecting tube from which small samples were removed immediately for hematocrit determination in heparinized capillary tubes. Blood smears were also made and fixed ( $3 \mathrm{~min}$ immersion in methanol) at the time of blood collection. The collecting tubes were kept at $0-4^{\circ} \mathrm{C}$ in cool containers that were carried to the laboratory where cell counting and biochemical analysis took place.

The blood samples reached the laboratory 12$36 \mathrm{hr}$ after collection and were treated as described previously (Puerta et al. 1989a) to obtain a uniform distribution of blood cells.

Aliquots of blood were diluted (200 and 50 times for red and white cells, respectively) in hematological pipettes with Natt and Herrick's (1952) solution. The number of erythrocytes and leukocytes were counted in 50 small squares and all the large squares of cell counting Thoma chambers, respectively. Hemoglobin was assayed according to the colorimetric method of Drabkin (1945).

Plasma was obtained by centrifugation and stored at $-20^{\circ} \mathrm{C}$ until analysis. Plasma proteins were assayed by the method of Lowry et al. (1951), using pigeon albumin as a standard (Sigma Chemical Co., St. Louis, Missouri). Triglycerides, cholesterol, urea, and uric acid were assayed with commercial kits (Cromatest Lab., Knickerbocker, Spain).

Blood smears were stained with commercial Giemsa stain (Merck, West Germany) diluted $1: 9(\mathrm{v} / \mathrm{v})$ in phosphate buffer, $\mathrm{pH} 7.8$, for $45 \mathrm{~min}$. Identification and counting of leukocytes and thrombocytes was done with a light microscope with oil immersion lens $(\times 100)$. At least 180 white cells were counted in each sample. The number of thrombocytes was transformed into absolute numbers by reference to the total number of white blood cells. No attempt was made to count immature forms of erythrocytes, or to differentiate large and small lymphocytes.
Statistical analysis was done by an unpaired Student's $t$-test. Values in the text are means \pm SE. $P<0.05$ was accepted as statistically significant.

\section{RESULTS}

The mean body weight of the 16 adults tested was $5,500 \pm 129 \mathrm{~g}$. The 13 young birds were smaller, with a mean body weight of $4,815 \pm$ $139 \mathrm{~g}$.

No statistically significant age differences existed in blood composition except in leukocyte number, differential counts of lymphocytes, and plasma levels of urea, uric acid, and triglycerides (Table 1).

No differences were found between adult and young birds in the numbers, dimensions, or hemoglobin content of red blood cells, or in numbers of thrombocytes (Table 1). The number of leukocytes was smaller in adult than in young cranes (Table 1). White cell differential counts were also different in mature and immature cranes. In adults, heterophils were the most abundant white cells (55\%), followed by lymphocytes (35\%). In young birds, numbers of heterophils and lymphocytes were similar (47\%). No age-related differences were detected in numbers of eosinophils, basophils, and monocytes. No correlation was found between body weight and numbers (total or differential) of thrombocytes, leukocytes, erythrocytes, or erythrocyte parameters for adults, young, or the whole group. It is interesting that both heterophils and eosinophils exhibited rod-shaped granules. However, the granules in eosinophils stained a uniform orange-red color, whereas those of heterophils were red-purple, and did not stain uniformly. Instead, one pole of the granules was most strongly stained which, at first sight, made it appear as if cytoplasm contained round granules.

No age-related differences were found in plasma levels of total proteins or cholesterol (Table 1). However, adult cranes had higher levels of urea and lower levels of triglycerides and uric acid than young birds. No correlation was found between these plasma levels and body weight.

\section{DISCUSSION}

The western population of Common Cranes migrates from the main breeding areas in Sweden through western Europe to the winter quarters in Spain in September-December. While adults have already participated in at least three mi- 
TABLE 1. Hematology and blood chemistry of Common Cranes overwintering at Gallocanta Lake. Hb: hemoglobin, Hc: hematocrit, MCHb: mean cell hemoglobin, MCHbC: mean cell hemoglobin concentration, MCV: mean cell volume, TG: triglycerides.

\begin{tabular}{lccc}
\hline \hline & Adults $(n=15-17)$ & Young $(n=12-13)$ & Whole group $(n=28-30)$ \\
\hline Erythrocytes $\left(\mathrm{cell} \cdot \mathrm{mm}^{-3}\right)$ & $2,424,783 \pm 82,183$ & $2,520,506 \pm 108,117$ & $2,467,697 \pm 65,812$ \\
$\mathrm{Hc}(\%)$ & $42.7 \pm 1.2$ & $43.1 \pm 1.3$ & $42.9 \pm 0.9$ \\
$\mathrm{Hb}(\mathrm{g} / 100 \mathrm{ml})$ & $14.6 \pm 0.6$ & $15.0 \pm 0.6$ & $14.8 \pm 0.4$ \\
$\mathrm{MCV}\left(\mu \mathrm{m}^{3}\right)$ & $176 \pm 5$ & $172 \pm 6$ & $174 \pm 4$ \\
$\mathrm{MCHb}(\mathrm{pg} / \mathrm{cell})$ & $60.4 \pm 1.8$ & $60.1 \pm 2.5$ & $60.3 \pm 1.5$ \\
MCHbC $(\mathrm{g} / 100 \mathrm{ml})$ & $34.4 \pm 1.1$ & $35.1 \pm 1.7$ & $34.7 \pm 0.9$ \\
Thrombocytes $\left(\mathrm{cell} \cdot \mathrm{mm}^{-3}\right)$ & $10,586 \pm 1,370$ & $7,353 \pm 1,241$ & $9,149 \pm 987$ \\
Leukocytes $\left(\mathrm{cell} \cdot \mathrm{mm}^{-3}\right)$ & $21,855 \pm 1,258$ & $28,054 \pm 1,469$ & - \\
Heterophils $(\%)$ & $55.4 \pm 2.6$ & $47.3 \pm 3.7$ & $51.8 \pm 2.3$ \\
Eosinophils $(\%)$ & $3.7 \pm 0.6$ & $3.0 \pm 0.6$ & $3.4 \pm 0.4$ \\
Basophils $(\%)$ & $1.9 \pm 0.2$ & $1.1 \pm 0.3$ & $1.5 \pm 0.2$ \\
Lymphocytes $(\%)$ & $35.8 \pm 2.8$ & $47.4 \pm 3.4 *$ & - \\
Monocytes $(\%)$ & $3.4 \pm 0.5$ & $2.5 \pm 0.4$ & $3.0 \pm 0.3$ \\
Total proteins $(\mathrm{g} / 100 \mathrm{ml})$ & $4.9 \pm 0.2$ & $4.8 \pm 0.1$ & $4.9 \pm 0.1$ \\
Uric acid $(\mathrm{mg} / 100 \mathrm{ml})$ & $2.9 \pm 0.4$ & $4.4 \pm 0.5 *$ & - \\
Urea $(\mathrm{mg} / 100 \mathrm{ml})$ & $7.1 \pm 0.4$ & $5.5 \pm 0.5^{*}$ & - \\
Cholesterol $(\mathrm{mg} / 100 \mathrm{ml})$ & $203 \pm 11$ & $195 \pm 15$ & $200 \pm 9$ \\
TG (mg/l00 ml) & $81 \pm 5$ & $110 \pm 8 *$ & - \\
\hline
\end{tabular}

${ }^{*} P<0.05,{ }^{* *} P<0.005$ for young birds vs. adults.

gratory flights, young birds have just completed their first such flight. Since flight increases the oxygen demands of birds (Lasiewski 1972, Berstein et al. 1973) and since hematocrit, hemoglobin content, and red cell numbers are higher in good fliers than in flightless species (Balasch et al. 1974, Viscor et al. 1985), it is not surprising that young and adult cranes had similar erythrocyte numbers, blood hemoglobin levels, and hematocrits (Table 1). We previously detected some increase in these parameters with age in chicks of another migratory species, the White Stork (Ciconia ciconia; Puerta et al. 1989a). However, White Stork chicks were examined at the nest, and had not yet undertaken a migratory flight. Therefore, it is tempting to speculate that, in migratory species, red cell number, and blood hemoglobin and hematocrit levels increase from the time the birds hatch until they complete their first migratory flight and then remain more or less stable, although the occurrence of seasonal changes cannot be ruled out.

Some previous papers deal with the hematology of cranes (Gee et al. 1981, Hawkey et al. 1983, Isaaks et al. 1987), but all of them were based on data from captive birds. After comparing previous results in captive Common Cranes (Table 2) with those presented here for free-living ones (Table 1), we suggest that cap- tivity may not significantly modify the number and volume of erythrocytes nor the blood hemoglobin content in this species, at least under the conditions in which the animals were previously studied. This is in accordance with deGraw et al. (1979) who reported that captive populations of Zonotrichia leucophrys gambelii show the same changes in blood composition as free-living populations.

Thrombocyte numbers are highly variable in birds. DeVilliers (cited by Sturkie 1986a) recorded $10.5 \times 10^{3} \mathrm{~mm}^{-3}$ in the Ostrich (Struthio camelus), whereas Nirmalan and Robinson (1971) recorded $137 \times 10^{3} \mathrm{~mm}^{-3}$ in the female Japanese Quail (Coturnix japonica). Most other

TABLE 2. Red blood cells of captive Common Cranes. $\mathrm{Hb}$ : hemoglobin, Hc: hematocrit, $\mathrm{MCHb}$ : mean cell hemoglobin, MCHbC: mean cell hemoglobin concentration, $\mathrm{MCV}$ : mean cell volume.

\begin{tabular}{lcc}
\hline \hline & $\begin{array}{c}\text { Isaaks et al. } \\
(1987)\end{array}$ & $\begin{array}{c}\text { Hawkey et al. } \\
(1983)\end{array}$ \\
\hline Animals tested & $10-19$ & 4 \\
Erythrocytes $\left(\right.$ cell $\left.\cdot \mathrm{mm}^{-3}\right)$ & $2.26 \times 10^{6}$ & $2.70 \times 10^{6}$ \\
Hc $(\%)$ & 43.2 & 48 \\
Hb $(\mathrm{g} / 100 \mathrm{ml})$ & 15.8 & 16.7 \\
$\mathrm{MCV}\left(\mu \mathrm{m}^{3}\right)$ & 230 & 177 \\
MCHb $(\mathrm{pg} /$ cell $)$ & - & 62.1 \\
MCHbC $(\mathrm{g} / 100 \mathrm{ml})$ & - & 34.9 \\
\hline
\end{tabular}


species studied have values intermediate to these (Sturkie 1986a). We have recorded $10.2 \times 10^{3}$ thrombocytes $\mathrm{mm}^{-3}$ in free-living Common Cranes, with no statistical difference between adult and young birds. On the other hand, Hawkey et al. (1983) published a mean value of 56 $\times 10^{3}$ thrombocytes $\mathrm{mm}^{-3}$ for four captive Common Cranes. However, individual variation was considerable $\left(18 \times 10^{3}-94 \times 10^{3}\right)$. Ratios of erythrocytes to thrombocytes as different as 353:1 (Nirmalan and Robinson 1971) and 35:1 (Puerta et al. 1989b) or lower (e.g., 22:1 [Puerta et al. 1989a]) exist. Our ratio, 240:1, differs substantially from the $48: 1$ published by Hawkey et al. (1983) for captive Common Cranes. We feel that captivity condition may modify thrombocyte numbers. The significance of this, if any, remains unexplained.

Most birds studied have leukocyte numbers of $15-30 \times 10^{3} \mathrm{~mm}^{-3}$ (for review see Sturkie 1986a). However, Hawkey et al. (1983) reported $10.2 \times$ $10^{3} \mathrm{~mm}^{-3}$ for captive Common Cranes, and even lower numbers for captive Demoiselle Cranes (Anthropoides virgo) and Manchurian Cranes (Grus japonensis). Our values for free-living Common Cranes (Table 1) are much higher than the latter, especially in young cranes. Two main conclusions can be inferred from these facts. Captivity diminishes the risk of infection and accordingly the number of leukocytes is smaller in captive animals than in free-living ones. On the other hand, such risk is probably higher in young animals given their high numbers of leukocytes. This is consistent with the fact that stork chicks at the nest have the highest number of leukocytes yet recorded in birds (Puerta et al. 1989a).

With few exceptions (Sturkie 1986a, Puerta et al. 1989a) lymphocytes are generally reported as the most abundant white cell type (Jones and Johansen 1972, Hodges 1979). But Hawkey et al. (1983) found twice as many heterophils as lymphocytes not only in Common Cranes, but also in eight other species of cranes. The adult free-living cranes examined here also had a greater proportion of heterophils than lymphocytes (Table 1). Accordingly, it does not appear that captivity changes the relative proportions of lymphocytes and heterophils in adults. However, it may alter the differential leukocyte count. Eosinophils made up $3.4 \%$ of the total leukocytes in free-living cranes (Table 1) but $21 \%$ in captives of the same species (Hawkey et al. 1983). On the other hand, differential leukocyte counts in freeliving cranes seem also age dependent (Table 1).

Plasma levels of total protein are similar in young and adult Common Cranes and in the range reported for other avian species (Sturkie 1986b). Although they are higher than levels recorded in other species of captive cranes (Gee et al. 1981), this difference cannot be attributed to captivity since no data are available for captive Common Cranes.

Plasma levels of urea, cholesterol, and triglycerides also lie within the range reported for other avian species, both captive (Gee et al. 1981, Puerta et al. 1989b) and free-living (Puerta et al. 1989a). In contrast, plasma uric acid levels are lower than those published for other captive (Gee et al. 1981, Sturkie 1986b, Puerta et al. 1989b) and free-living species (Puerta et al. 1989a). Since the blood level of this compound diminishes during starvation (Sykes 1971) and taking into account that blood was sampled during the autumn migration of the cranes, the low blood uric acid level measured may be indicative of feeding restraint. Moreover, this assumption is reinforced by the fact that plasma levels are higher in young than in adult cranes (Table 1), which suggests that, although absolute food intake rate is lower in juveniles than in adults (unpubl. data), they suffer relatively less from possible food shortage conditions than adults, due to their lower food requirements as a consequence of their lower body weight, and to the prolonged parental care in this species (Alonso et al. 1984b). The higher plasma triglycerides content of young birds correlates well with this.

\section{ACKNOWLEDGMENT}

Fieldwork was supported by the DGICYT Project No. PB0389.

\section{LITERATURE CITED}

Alonso, J. A., J. C. Alonso, and J. P. Veiga. 1984a. Winter feeding ecology of the Crane in cereal farmland at Gallocanta, Spain. Wildfowl 35:119-135.

Alonso, J. C., J. P. Veiga, AND J. A. Alonso. 1984b. Familienauflösung und Abzug aus dem Winterquartier beim Kranich Grus grus. J. Ornithol. 125: 69-74.

Balasch, J., J. Palomeque, L. Palacios, S. Musquera, AND M. JIMENEZ. 1974. Hematological values of some great flying and aquatic-diving birds. Comp. Biochem. Physiol. A. Comp. Physiol. 49:137-145.

Berstein, M. H., S. P. Thomas, and K. SchmidtNielsen. 1973. Power input during flight of the fish crow Corvus ossifragus. J. Exp. Biol. 58:401410 . 
Chilgren, J., AND W. A. deGraw. 1977. Some blood characteristics of White-crowned Sparrows during molt. Auk 94:169-171.

Cramp, S., AND K.E.L. Simmons [eDs.]. 1980. The birds of the Western Palearctic. Vol. II. Oxford Univ. Press, Oxford.

DEGraw, W. A., M. D. KeRN, AND J. R. KING. 1979. Seasonal changes in the blood composition of captive and free-living White-crowned Sparrows. J. Comp. Physiol. 129:151-162.

Dieterlen-Lievre, F. 1988. Birds, p. 257-336. In A. F. Rowley and N. A. Ratcliff [eds.], Vertebrate blood cells. Cambridge Univ. Press, Cambridge.

DrabkIN, D. R. 1945. Crystallographic and optical properties of human hemoglobin. A proposal for the standardization of hemoglobin. Am. J. Med. Sci. 209:268-270.

Gee, G. F., J. W. Carpenter, and G. L. Hensler. 1981. Species differences in hematological values of captive cranes, geese, raptors and quail. J. Wildl. Manage. 45:463-483.

Hawkey, C., J. H. Samour, D. G. Ashton, M. G. HART, R. N. Cindery, J. M. Finch, AND D. M. JoNes. 1983. Normal and clinical haematology of captive cranes (Gruiformes). Avian Pathol. 12: 73-84.

HoDges, R. D. 1979 . The blood cells, p. 361-380. In A. S. King and J. McLelland [eds.], Form and function in birds. Vol. 1. Academic Press, London.

Isaaks, R. E., C. Y. Kim, P. H. Goldman, M. S. Putman, C. M. Mirande, and D. R. Harkness. 1987. Studies on avian erythrocyte metabolismXV. Relationship between the major phosphorylated metabolic intermediates and whole blood oxygen affinity in the Gruiformes (cranes). Comp. Biochem. Physiol. 87B:165-169.

JoNes, D. R., AND K. JoHANSEN. 1972. The blood vascular system of birds, p. 158-287. In D. S. Farner and J. R. King [eds.], Avian biology. Vol. 2. Academic Press, New York.

KERN, M. D., W. A. DEGRAW, AND J. R. KING. 1972.
Effects of gonadal hormones on the blood composition of White-crowned Sparrows. Gen. Comp. Endocrinol. 18:43-53.

LASIEWSKI, R. C. 1972. Respiratory function in birds, p. 288-342. In D. S. Farner and J. R. King [eds.], Avian biology. Vol. 2. Academic Press, New York. Lowry, O. H., N. J. Rosebrough, A. L. FARR, AND R. J. Randall. 1951. Protein measurement with the Folin phenol reagent. J. Biol. Chem. 193:265275.

NATt, M. P., AND C. A. HerRick. 1952. A new blood diluent for counting the erythrocytes and leucocytes of the chicken. Poult. Sci. 31:735-738.

Nirmalan, G. P., and G. A. Robinson. 1971. Hematology of Japanese Quail, Coturnix japonica. Br. Poult. Sci. 12:475-479.

Puerta, M. L., R. Muñoz Pulido, V. Huecas, and M. AbelendA. 1989a. Hematology and blood chemistry of White and Black Storks (Ciconia ciconia and Ciconia nigra). A. Comp. Physiol. 94: 201-204.

Puerta, M. L., V. Huecas, and A. L. Garcia del CAMPO. 1989b. Hematology and blood chemistry of the Chilean Flamingo. Comp. Biochem. Physiol.

STURKIE, P. D. 1986a. Body fluids: Blood, p. 102120. In P. D. Sturkie [ed.], Avian physiology. 4th ed. Springer-Verlag, Berlin.

StURKIE, P. D. 1986b. Kidneys, extrarenal salt secretion and urine, p. 359-382. In P. D. Sturkie [ed.], Avian physiology. 4th ed. Springer-Verlag, Berlin.

SYkes, A. H. 1971. Formation and composition of urine, p. 358-397. In D. J. Bell and B. M. Freeman [eds.], Physiology and biochemistry of the fowl. Academic Press, New York.

Viscor, G., M. S. Marques, AND J. Palomeque. 1985. Cardiovascular and organ weight adaptations as related to flight activity in birds. Comp. Biochem. Physiol. A Comp. Physiol. 82:597-599. 